\title{
Comment on: International ERS/ATS guidelines on definition, evaluation and treatment of severe asthma
}

To the Editor:

I was pleased to see that the new guidelines on severe asthma use the GRADE (Grading of Recommendations, Assessment, Development and Evaluation) system to classify the strength of evidence behind each expert recommendation [1]. The fact that the strength of most of the recommendations was "conditional" (i.e. many patients and clinicians might choose an alternative approach) and was based on "low" or "very low" quality evidence illustrates the need for further and better research. I suggest further refinements to asthma guidelines that will promote informed choices by both patients and clinicians. 1) Unbiased accounting of the benefits and harm in terms that are understood by both patients and clinicians. 2) This requires a systematic rather than a non-systematic literature review.

The "macrolide antibiotics" recommendation (conditional, very low quality evidence) is a good example of why a systematic review should be part of any guideline. The European Respiratory Society/American Thoracic Society recommendation is that clinicians should not use macrolides for severe asthma, noting that this recommendation placed a relatively higher value on the prevention of developing antibiotic resistance and a relatively lower value on uncertain benefits. This recommendation may be reasonable from the perspective of the guideline developers but in my experience is not usually accepted by patients with severe and/or refractory asthma. Clinicians and patients would have been better served had the authors cited the emerging evidence for the benefit of macrolides for the long-term management of asthma [2] and the lack of evidence for patient harm caused by macrolide resistance [3-5]. One could then construct a decision aid displaying the known/possible benefits and harm, including the quality, quantity and strength of evidence for each benefit and harm.

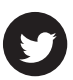

@ERSpublications

Guidelines must include unbiased systematic reviews of available evidence and take patient preferences into account http://ow.ly/vcJZP

David L. Hahn

University of Wisconsin School of Medicine and Public Health, Madison, WI, USA.

Correspondence: David L. Hahn, University of Wisconsin School of Medicine and Public Health 1100 Delaplaine Ct., Madison, WI 53715-1896, USA. E-mail: dlhahn@wisc.edu

Received: Feb 242014 | Accepted: Feb 262014

Conflict of interest: None declared.

\section{References}

Chung KF, Wenzel SE, Brozek JL, et al. International ERS/ATS guidelines on definition, evaluation and treatment of severe asthma. Eur Respir J 2014; 43: 343-373.

2 Reiter J, Demirel N, Mendy A, et al. Macrolides for the long-term management of asthma - a meta-analysis of randomized clinical trials. Allergy 2013; 68: 1040-1049.

3 Grayston JT, Kronmal RA, Jackson LA, et al. Azithromycin for the secondary prevention of coronary events. N Engl $J$ Med 2005; 352: 1637-1645.

4 O'Connor CM, Dunne MW, Pfeffer MA, et al. Azithomycin for the secondary prevention of coronary heart disease events. The WIZARD Study: a randomized controlled trial. JAMA 2003; 290: 1459-1466.

5 Hahn DL. Azithromycin for prevention of exacerbations of COPD. N Engl J Med 2011; 365: 2235-2237. 